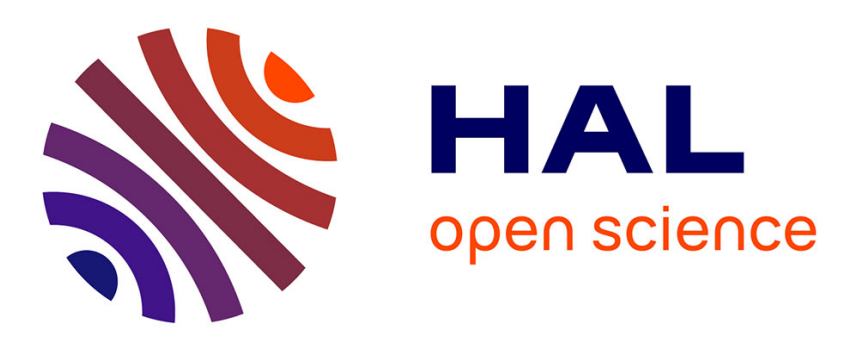

\title{
Formation and Features of Adiabatic Shear Bands in Zr-Nb Alloys in Spherical Stress Waves
}

\author{
A. Dobromyslov, E. Kozlov, N. Taluts
}

\section{To cite this version:}

A. Dobromyslov, E. Kozlov, N. Taluts. Formation and Features of Adiabatic Shear Bands in Zr-Nb Alloys in Spherical Stress Waves. Journal de Physique IV Proceedings, 1997, 07 (C3), pp.C3-963-C3967. 10.1051/jp4:19973162 . jpa-00255452

\section{HAL Id: jpa-00255452 https://hal.science/jpa-00255452}

Submitted on 1 Jan 1997

HAL is a multi-disciplinary open access archive for the deposit and dissemination of scientific research documents, whether they are published or not. The documents may come from teaching and research institutions in France or abroad, or from public or private research centers.
L'archive ouverte pluridisciplinaire HAL, est destinée au dépôt et à la diffusion de documents scientifiques de niveau recherche, publiés ou non, émanant des établissements d'enseignement et de recherche français ou étrangers, des laboratoires publics ou privés. 


\title{
Formation and Features of Adiabatic Shear Bands in Zr-Nb Alloys in Spherical Stress Waves
}

\author{
A.V. Dobromyslov, E.A. Kozlov* and N.I. Taluts \\ Institute of Metal Physics, Ural Division of Russian Academy of Sciences, 18 S. Kovalevskaya str., \\ GSP 170, Ekaterinburg 620219, Russia \\ * Russian Federal Nuclear Center, Research Institute of Technical Physics, P.O. Box 245, Snezhinsk \\ (Chelyabinsk 70), Chelyabinsk region 456770, Russia
}

\begin{abstract}
The adiabatic shear bands produced under loading by spherical stress waves in $\mathrm{Zr}-\mathrm{Nb}$ alloys was studied by optical and transmission electron microscopy. The structure and distribution of the adiabatic shear bands were established depending on the loading conditions and the niobium content.

Résumé. Nous avons étudié par microscopie optique et électronique les bandes de cisaillement adiabatique produite sous la charge par les ondes sphérique tension dans les alliages $\mathrm{Zr}-\mathrm{Nb}$. Les effects de conditions charge et contenu du niobium sur la structure et la distribution de les bandes de cisaillement adiabatique sont présentés.
\end{abstract}

\section{INTRODUCTION}

Adiabatic shear bands (ASB) can form in materials at high strain rates and levels of strain. These conditions realize during shock wave loading. The ASBs arise due to instabilities of plastic flow. The ASBs are characterized by highly localized large deformation and the adiabaticity of the process. Recently several investigations of the ASBs were performed [1-3]. The impact by flyer plate technique was used in all these investigations. The observation of the ASBs under loading zirconium by spherical converging stress waves was reported in [4]. The purpose of the present work is to study the formation of the ASBs in $\mathrm{Zr}-\mathrm{Nb}$ alloys with 1 and $2.5 \mathrm{wt}$ \% niobium under loading by spherical converging stress waves of the different intensity.

\section{EXPERIMENTAL}

Two balls of $\mathrm{Zr}-1 \mathrm{wt} . \% \mathrm{Nb}$ alloy 35 and $32 \mathrm{~mm}$ in radii and two balls of $\mathrm{Zr}-2.5 \mathrm{wt} . \% \mathrm{Nb}$ alloy of the same sizes were subjected to the loading by spherical converging detonation waves of the different intensity. The external radius of the explosive was $40 \mathrm{~mm}$. The experiments were performed with various compositions and thickness of the explosive, as well as with or without a heavy case. The initial pressure on the external surface of the balls was over $30 \mathrm{GPa}$. In the central areas of the balls pressures and temperatures, sufficient for the melting of the alloys directly at the shock-wave front, were reached at converging waves. The detailed analysis of the structure was performed using the optical microscopes, including an optical microscope with a polarized light, and an electron microscope JEM-100C.

\section{RESULTS AND DISCUSSION}

The specimens that were saved unbroken after the shock loading with spherical converging stress waves have the shape of a thick-wall spherical shell with an outer diameter somewhat increased compared to that of the initial unloaded balls. In the central part of the initially continuous ball there appeared a hollow whose size was different in different specimens. Therefore, the average volume deformations of the specimens were different. Local deformation changes over a wide range along the radius. Due to loading scheme, the failure of the ball begins in its center and causes the formation of the hollow. A special feature 
wave formed after the focusing of the spherical converging wave in the ball's center. In all balls, the fracture surfaces bear evidence of ductile fracture. Figure 1 shows a view of section of the ball made of $\mathrm{Zr}-1 \mathrm{wt} . \% \mathrm{Nb}$ alloy after high-intense loading.

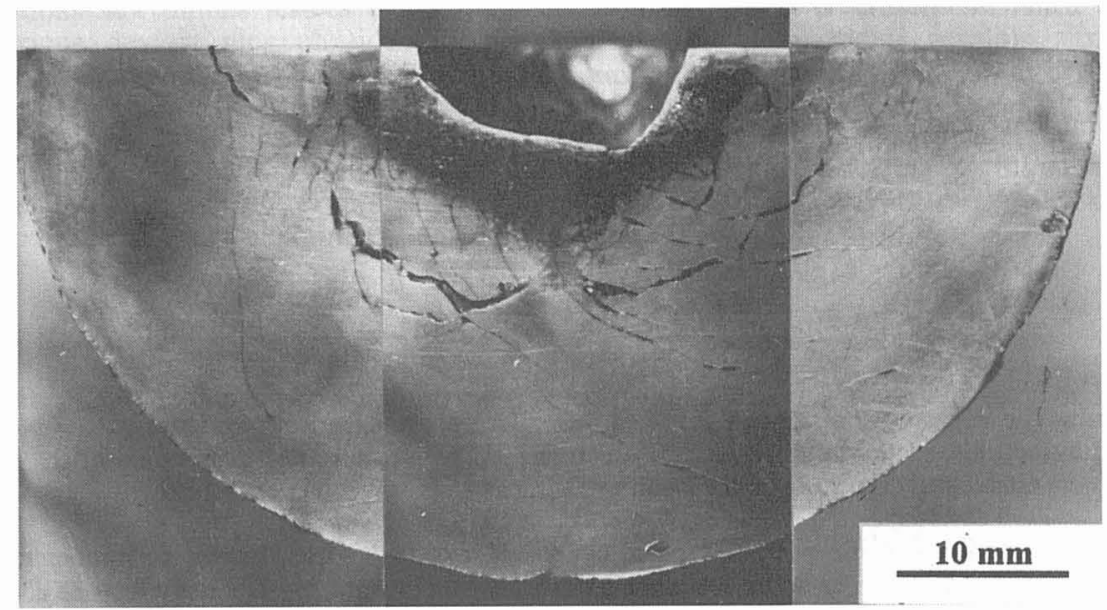

Figure 1: The view of section of the ball made of $\mathrm{Zr}-1 \mathrm{wt} \% \mathrm{Nb}$ alloy after high-intense loading.

As the result of spherical converging detonation waves loading, the great amount of the ASBs was observed in the balls. It was found that the amount of the ASBs and their distribution depends both on the loading conditions and on the niobium content in the alloy, but the loading intensity being essential factor than the niobium content. In the case of low-intense loading, the ASBs formation occurs in deep layers, predominantly near the hollow of the plastic failure formed in the centre of each ball. Figure 2 shows the ASBs distribution in $\mathrm{Zr}-2.5 \mathrm{wt} . \% \mathrm{Nb}$ alloy near the hollow. The high-intense loading results in increase of the ASBs amount in the balls, and the ASBs are observed in all layers not depending on their depth in the ball (Figure 1).

In addition to the radially directed ASBs formed during compression (at the front of the spherical converging wave), the $\mathrm{ASBs}$ oriented at an angle (up to angles of about $90^{\circ}$ ) to radial directions are also revealed in the loaded specimens. In the most cases, the ASBs propagate curvilinearly (Figure 3 ). The ASBs are sometimes dendrite-like by branching into several finer bands (Figure 4). However, the branching of the ASBs is observed more rarely in $\mathrm{Zr}-\mathrm{Nb}$ alloys then in pure zirconium [4]. The structural defects such as grain boundaries, twins, dislocations, cracks, pores do not prevent the ASBs propagation. The cross-section of ASBs was studied. It was found that ASBs have the form of extended ribbons with different thickness and width. The view of an ASB at two perpendicular surfaces is shown in Figure 5

It is observed the formation of several melting areas and pores inside the ASBs spaced at some distance apart (Figures 2 and $4 \mathrm{~b}$ ). The existence of pores within the ASB shows that the material was heated to the vapour state in these places.

Cracks of various shapes and sizes are observed in the balls after loading. Cracks of the following three types are revealed in the specimens: radial cracks, concentric cracks near the hollow, and cracks near the loading surface of the ball (Figure 1). It was studied the relation of the ASBs with cracks formed in the balls. It was established that in some cases the ASBs are the sources of the cracks formation. This phenomenon is associated with the decrease of the strength of material in the ASB.

The internal structure of ASBs depends on loading conditions. In the case of low-intense loading, the ASBs have very fine-grained structure. The electron microscope study shows that the grain size in such ASBs ranges from 0.1 to $0.3 \mu \mathrm{m}$. In case of high-intense loading, the ASBs containing coarser grains are observed together with the fine-grained bands. Being examined in a polarized light, the coarser grains exhibit various contrast. This gives evidence of a great misorientation between these grains. Moreover, the 
martensite structure is observed within the ASBs in deep layers under high-intense loading. This indicates that the conditions required for $\beta \rightarrow \alpha$ transformation were realized in this case.

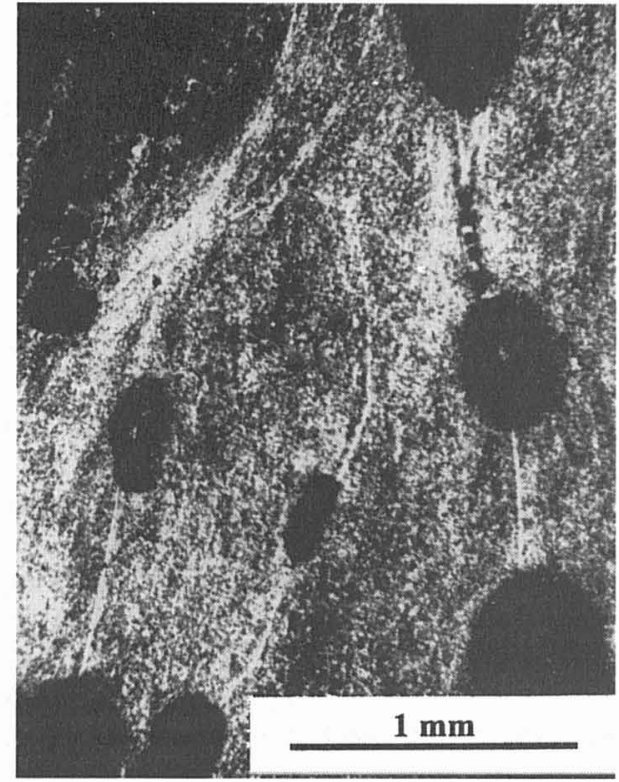

Figure 2: The ASBs distribution in $\mathrm{Zx}-2.5 \mathrm{wt} \% \mathrm{Nb}$ alloy near the hollow after low-intense loading.

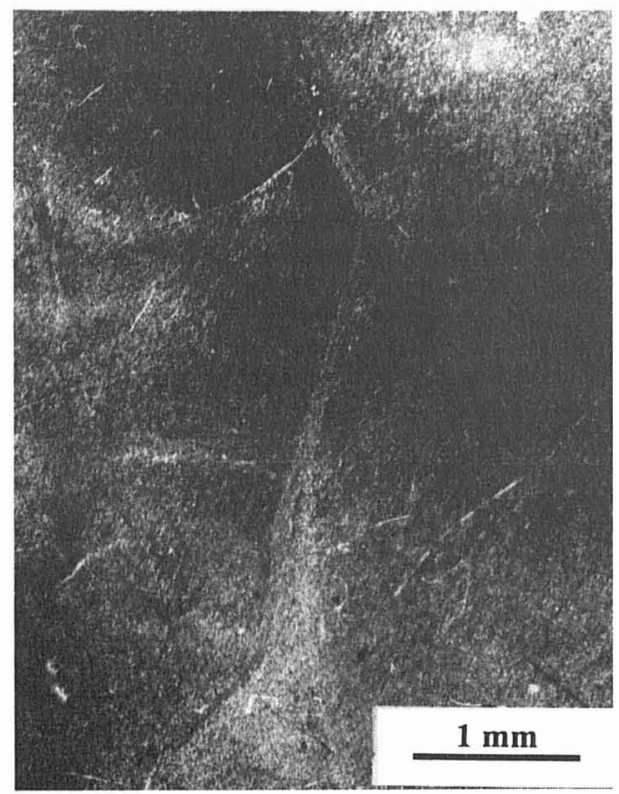

a)

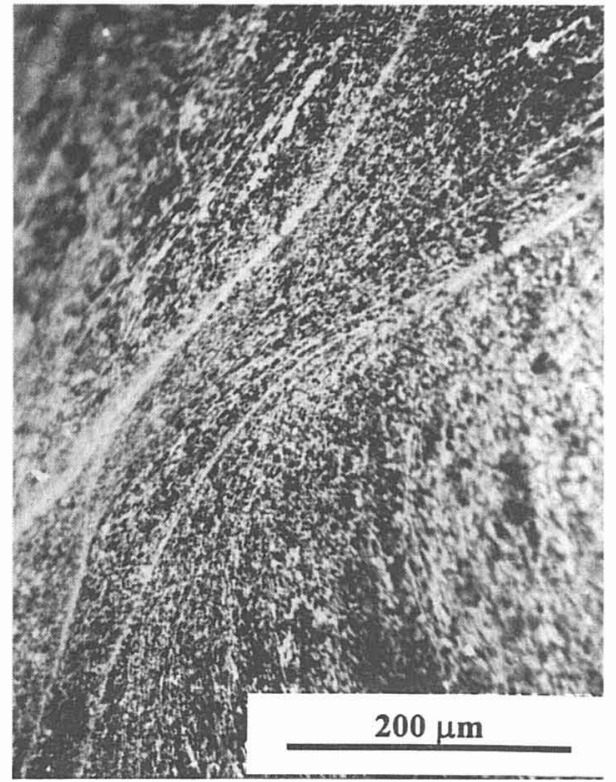

Figure 3: The ASBs in $\mathrm{Zr}-2.5 \mathrm{wt} . \% \mathrm{Nb}$ alloy after lowintense loading.

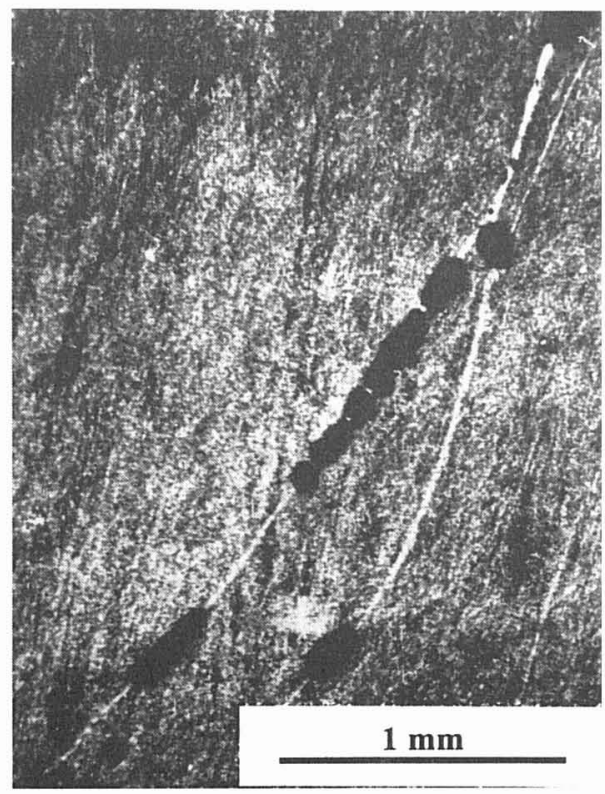

b)

Figure 4: The branching of ASBs after high-intense loading: a) in $\mathrm{Zr}$-lwt.\% $\mathrm{Nb}$ alloy (in polarized light) and b) in $\mathrm{Zr}-2.5 \mathrm{wt} . \% \mathrm{Nb}$ alloy. 
(१ग् әपा प०

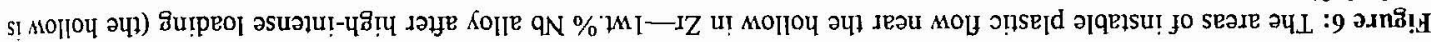

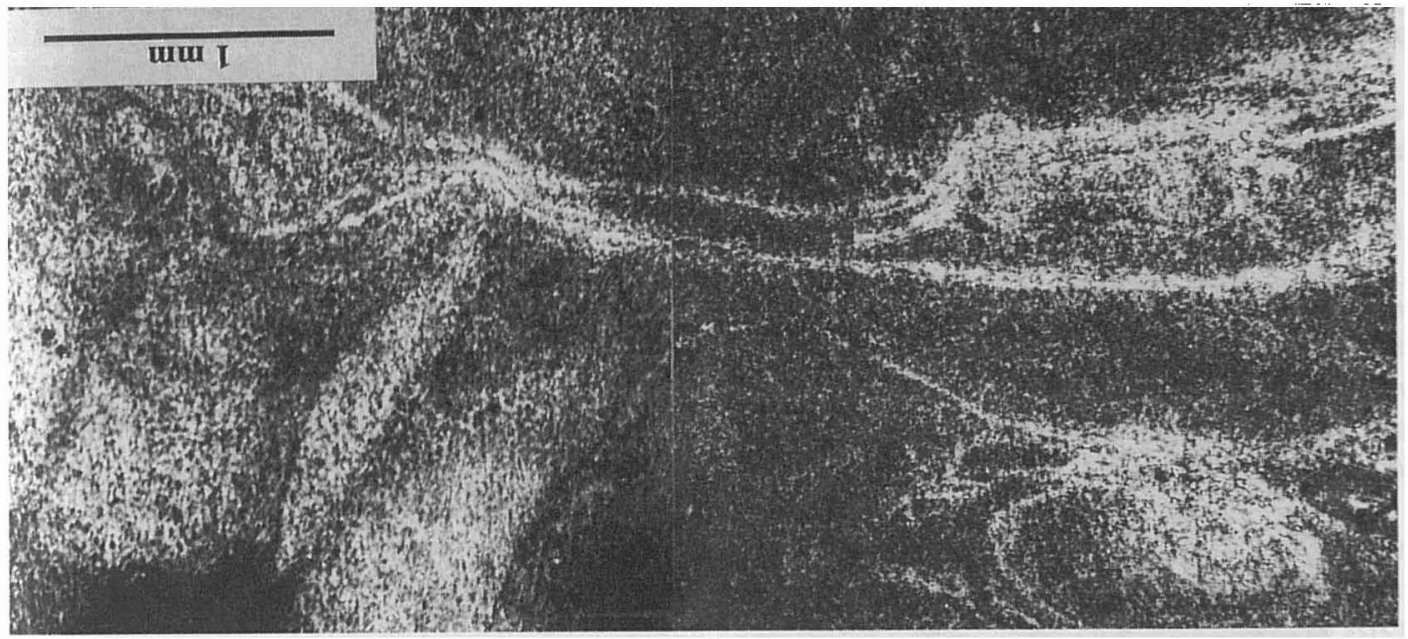

[t] suon!puos oిuाpeo] snoso

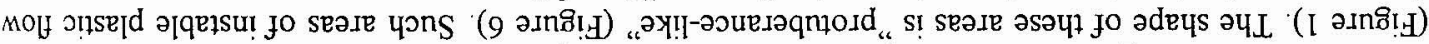

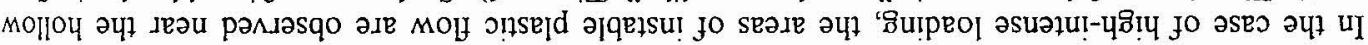

'รి
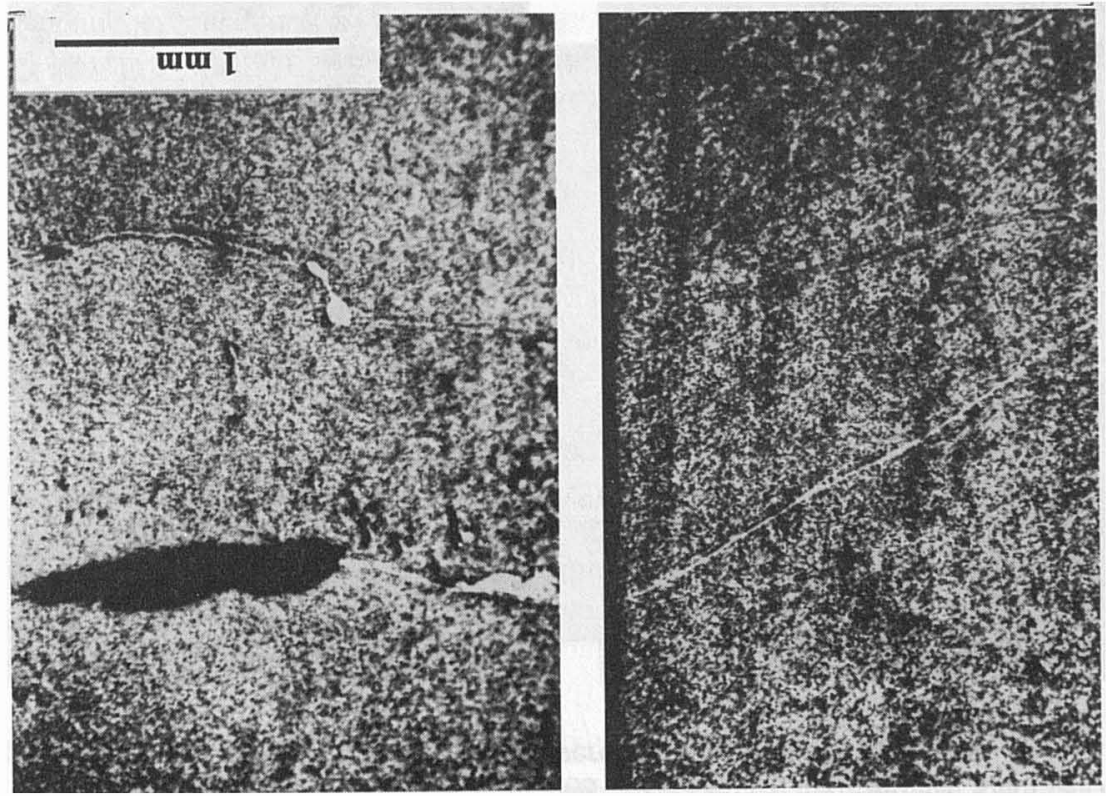


\section{CONCLUSION}

Formation of the ASBs in $\mathrm{Zr}-\mathrm{Nb}$ alloys loaded by spherical stress waves of various intensity was investigated. It was found that the amount of the ASBs and their distribution in the ball are determined mainly by the loading intensity but not the niobium content. The structural features of the ASBs (the fine structure of ASBs, the branching of ASBs, the presence of ultrafine recrystallized grains within ASBs) were established. The melting areas and pores in the ASBs exist in all investigated specimens. The martensite structure within the ASBs is observed in deep layers under high-intense loading. The $\alpha-\omega-\beta-\mathrm{L}-$ vapour phase transformations in the ASBs can occur. It was shown that under loading of material by spherical stress waves the ASBs have the form of extended ribbons with different thickness and width.

\section{Acknowledgments}

This work was supported by the Russian Foundation for Fundamental Research, project no. 96-02-18438.

\section{References}

[1] Meyers M.A. and Park H.-R., Acta metall. 34 (1986) 2493-2499.

[2] Zurek A.K., Metall. and Mater. Trans. A 25A (1994) 2483-2489.

[3] Yang Y., Xinming Z., Zhenghua L., and Qingyun L., Acta melall. 44 (1996) 561-565.

[4] Kozlov E.A., Litvinov B.V., Abakshin E.V., Dobromyslov A.V., Taluts N.I., Kazantseva N.V., and Taluts G.G., Phys. Met. and Metallog. 79 (1995) 662-672. 